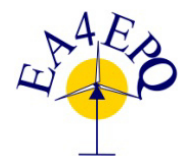

International Conference on Renewable Energies and Power Quality (ICREPQ'17)

Malaga (Spain), $4^{\text {th }}$ to $6^{\text {th }}$ April, 2017

Renewable Energy and Pourer Qualily. Fournal (RE\&PQJ)

ISSN 2172-038 X, No.15 April 2017

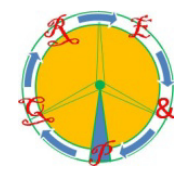

\title{
A comparative assessment of different alternatives to repower transmission corridors for the future supergrid
}

\author{
M. Borau-Rumbao, P. Cruz-Romero, A. de-la-Villa-Jaén. \\ Department of Electrical Engineering \\ Escuela Técnica Superior de Ingeniería, Universidad de Sevilla \\ Camino de los Descubrimientos s/n, 41092 Sevilla (Spain) \\ Phone: +0034 954 481277/79, e-mail: plcruz@us.es, adelavilla@us.es
}

\begin{abstract}
In order to allow the integration of the maximum amount of renewable energy in the European network, it is necessary to think about different solutions that meet the technical requirements at the same time that are compatible with the investment shortage. One option could be the development of a supergrid based on the uprating of the existing transmission system. In this paper, three different alternatives are proposed. The first two options require the installation of an upper module, being the difference of both options in the transmission technology: HVAC or HVDC. The third option consists in mixing both technologies, making use of the existing double circuit towers. At the end, a comparison between the three alternatives is shown.
\end{abstract}

\section{Key words}

Supergrid, uprating, HVAC, HVDC, hybrid.

\section{Introduction}

The integration of the maximum amount of renewable energy is one of the most important challenges for the European electrical system [1]. The potential of solar power in the North of Africa and of wind power in the North Sea could be a great opportunity to achieve the full decarbonisation of the electrical sector. Integrating this amount of energy is only possible with a reinforcement of the existing transmission system in the form of a new grid coined as supergrid [2]. This solution would also help to enhance the security of supply and to increase the energy efficiency [3].

However, investments for new overhead transmission infrastructures are being delayed mainly due to the social opposition to the construction of new lines. This paper proposes the uprating of some transmission corridors, keeping the $400 \mathrm{kV}$ lines with the same ampacity and adding a new UHV overlay layer. The new lines, at most, would be located in the existing towers using an upper module. This solution is more prone to be accepted by the citizenship.
Regarding the transmission technology, the use of HVAC (high voltage alternating current) or HVDC (high voltage direct current) technology in a determined transmission system would depend on technical and economic feasibilities. Where it is needed to transmit from far offshore generation or through buried cables it would be more convenient the use of HVDC technology. Besides, HVDC is able to transmit with lower losses. On the contrary, the difficulty of current construction and operation of DC meshed systems would justify the use of HVAC technology.

In this paper, three different transmission alternatives for the development of the supergrid are shown. The first two alternatives require an upper module to hold the new lines. The difference between both options is found in the transmission technology: HVAC and HVDC. The third option consists in a hybrid system where both technologies coexist. Sometimes, this option will require the conversion of double circuit AC systems to the hybrid one, but in other cases, where double circuit infrastructure is installed but not being used, apart from small modifications, the addition of the HVDC line would be enough.

The proposed technology for HVDC is based on VSC (voltage source converter), which is expected to be developed to transmit a big amount of power at the desired voltage level (500 kV DC). It uses IGBTs, so it is able to create an independent AC voltage, what allows the connection of islanded grids, and offers the capability of black-start, allowing the restoration of the system when needed [3].

The paper finishes with a comparison between the three alternatives and the conclusions. 


\section{Alternative 1}

The first alternative consists in the installation of an upper module, which would hold the new conductors. Therefore, structures (towers and foundations) must be modified. The tower must be adapted to hold the upper module and, consequently, foundations should also be reinforced. To achieve the desired capacity increase, this upper module would consist of a simple circuit with five subconductors in each phase.

One of the possible options for the upper module that could be installed, apart from the necessary modifications to adapt itself to the existing tower, is shown in Fig. 1. This support is frequently used in the European transmission system, but it will also need some modifications to be adapted to the desired voltage level $(800 \mathrm{kV})$.

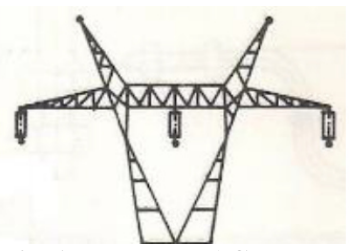

Fig. 1: Upper HVAC support

Thus, the total inversion costs include the necessary material, like the upper module and the existing structure reinforcement, the new substations, accessories costs and labour costs. As shown in Fig. 1, this alternative requires two ground wires (which will be reused) and three phases of five subconductors each.

At least, two substations will be required, one at each end of the line. Studied costs for a $1000 \mathrm{~km}$ line length with two substations are summarised in Fig. 2. Alternative 1 is the configuration which presents the biggest losses, due to the Joule and corona effects. Electrical losses in this alternative are about $8 \%$, including lines and substations losses. This makes alternative 1 to be, initially, an expensive option in comparison with alternatives 2 and 3 .

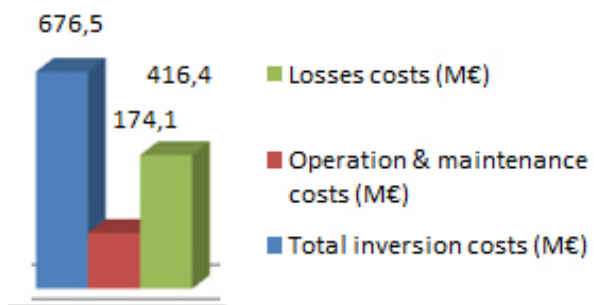

Fig. 2: Costs for HVAC configuration

However, one of the positive points of this alternative is that HVAC substations are much less expensive than HVDC ones and they also have lower losses. When more substations are needed, this option becomes even more interesting. Moreover, the fact that it is not necessary the disassembly of the existing line means that the labour costs are also smaller [4]. This also implies that time of works are reduced, keeping the line active as long as possible.

\section{Alternative 2}

In a very similar way than presented for alternative 1 , alternative 2 also needs an upper module, which will hold the new lines. Because of the simplicity of HVDC technology, this module will be simpler than presented for alternative 1 . Consequently, the modification in the existing structure will be lower, as well as the necessity of firming up the foundations.

Fig 3 shows a possible alternative for this upper HVDC module. As in the previous case, some modifications will be needed for the optimal adaptation of this module in the existing tower and also to guarantee the electrical distances for the desired voltage level $(500 \mathrm{kV})$.

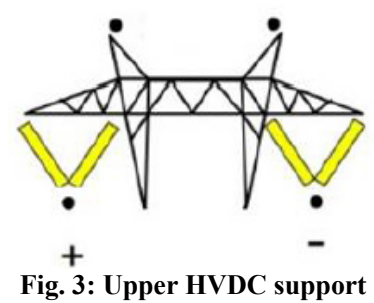

Costs for this alternative are shown in Fig. 4, where it is apparent the losses costs reduction, compared with alternative 1. Electrical losses in this alternative are about $6 \%$, including lines and substations losses. On the other hand, total inversion costs are higher than the ones presented in alternative 1 . Having reduced the number of subconductors (from 15 to 10), the upper module configuration is lighter than the one presented in alternative 1. In the same way than presented in alternative 1, ground wires will be reused.

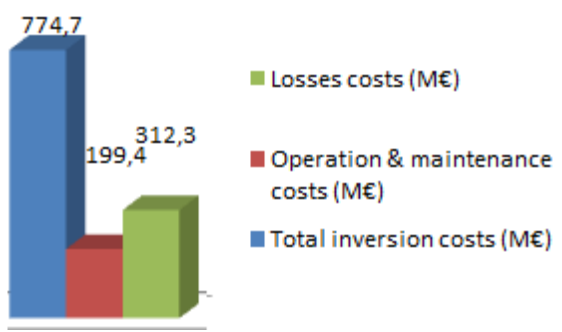

Fig. 4: Costs for HVDC configuration

The reason for needing a greater investment is the high cost of the HVDC substations that would make this alternative very expensive when a bigger number of substations is needed. Other costs that are included in the total inversion cost, apart from labour costs, are the upper module, the reinforcement for the existing structures and the new lines and accessories. In this alternative, instead of three phases, only two DC poles will be needed. Each pole will be composed of five subconductors, as in the previous case.

As in the previous case, there is no need of disassembling and assembling the existing lines, what implies a lower labour cost and shorter execution times of works, reducing the impact that disablement of the existing line would have [5]. Another positive point is that it is possible the use of a lower voltage to transmit the same 
amount of power. HVDC systems have a transmission capability between two and five times higher at the same voltage level [6]. Besides, losses in HVDC are lower than in HVAC, and finally, HVDC technology does not generate variable magnetic fields, so it is probable that fewer rejections would be found for this option. Ultimately, the upper module would be simpler, since fewer conductors are needed.

\section{Alternative 3}

The third alternative presented consists in the conversion of the existing double circuit AC system to a hybrid system, composed of a circuit of AC and other of DC. A first scheme is shown in Fig. 5. HVDC circuit is achieved by a rearrangement of conductors. The upper phase of this circuit must be separated, and each of the two subconductors should be added to the two lower phases, forming a bipole DC system with three subconductors in each pole [7].

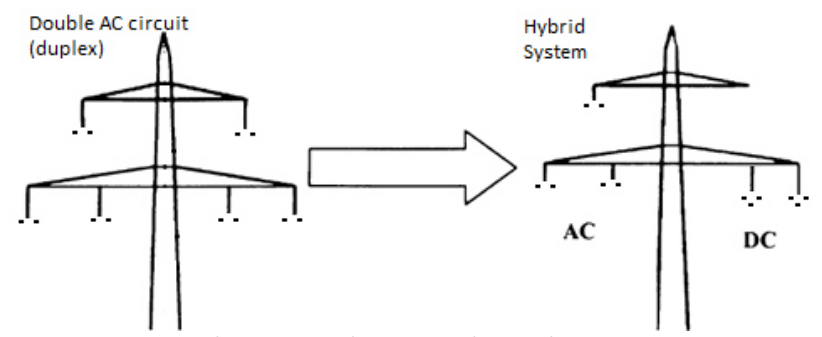

Fig. 5: Hybrid conversion - First step

With this configuration, transmission capacity increase about $60 \%$, what is an insufficient improvement. To guarantee the transmission of the required power, it is of vital importance to keep the current HVAC capacity, what will be achieved by adding more conductors in the $\mathrm{AC}$ circuit. For this purpose, the following configuration (Fig. 6) is proposed. HVAC circuit needs to be converted from duplex to quadruplex.

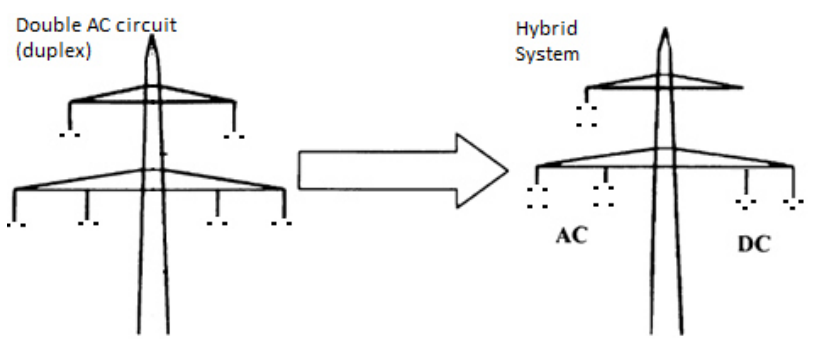

Fig. 6: Hybrid conversion - Second step

With this modification, the transmission capacity achieved is similar to previous alternatives. Besides, as it is shown in Fig. 7, the HVAC circuit could also be rearranged to achieve a better weight distribution.

For the conversion, conductors from both circuits must be disassembled and rearranged to conform the new circuits. In Fig. 8, it is possible to analyse the different costs associated to this alternative. Total inversion costs include, apart from the necessary HVDC substations, the cost of conditioning the HVAC substations to the new configuration. Losses for this alternative have been assumed to be about $6 \%$, the same losses than alternative 2.

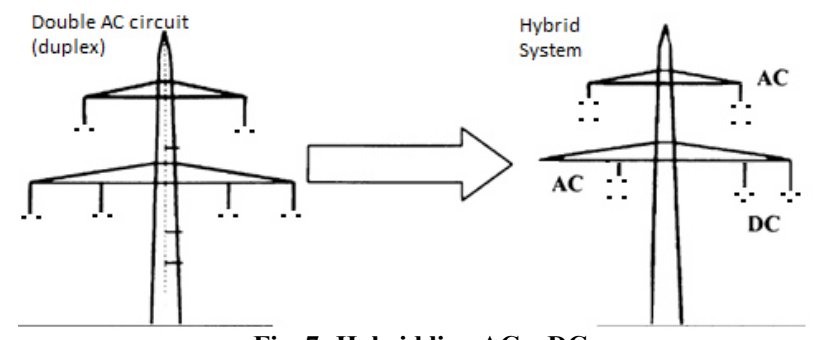

Fig. 7: Hybrid line AC - DC

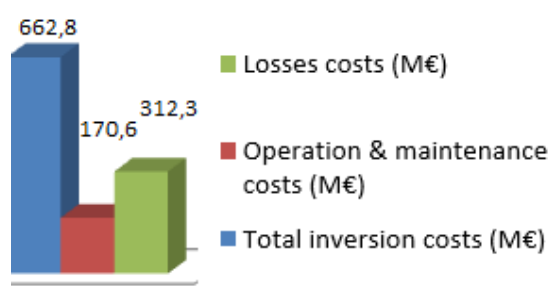

Fig. 8: Costs for hybrid configuration

Hypothetical economic advantages for this third option are not as good as expected. The necessity to modify both circuits to keep the current capacity forces to add new conductors and to have greater labour costs. Besides, in this alternative, execution times will be much longer because of the need of disassembling both circuits. Temporally, works of each circuit could be carried out separately, remaining active only one circuit and losing, in this way, half of the transmission capacity for a long time.

\section{Case study}

The three alternatives have been studied for an hypothetical initial system of $1.000 \mathrm{~km}$ and $400 \mathrm{kV}$. The considered span is $220 \mathrm{~m}$, which is a typical value for this system. The initial system which has been studied for the comparison of the three alternatives presents a duplex and double circuit configuration, as shown in Fig. 9. The desired increase in transmission capacity is approximately $2 \mathrm{GW}$. The used conductor in both systems (existing and new layer) is assumed to be Cardinal LA-545. Ground wires will be reused in the new structures.

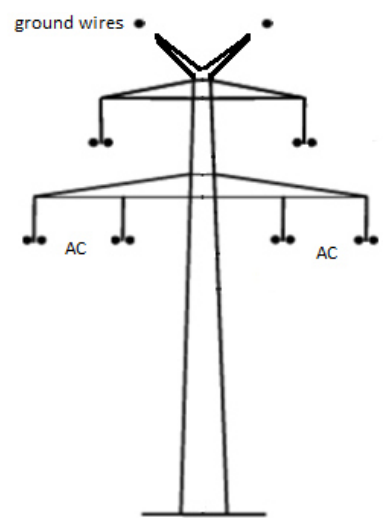

Fig. 9: Hypothetical initial system studied for the comparison

The useful life has been considered to be 40 years and it has also been considered that the system will be 
operational $90 \%$ of the time. To evaluate the economic cost, energy price has been supposed to be $50 € / \mathrm{MWh}$, which was the average price in the wholesale market in Spain in 2015.

The final configuration of the three alternatives is shown in Fig. 10. Red colour is used to represent the necessary reinforcement in alternatives 1 and 2. Although it will be also necessary a reinforcement in alternative 3 , the difference between the first two alternatives and the third one is relevant.
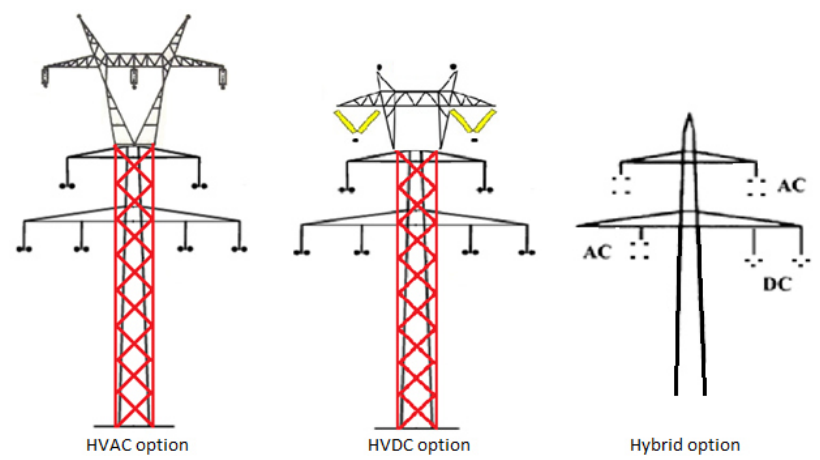

Fig. 10: Configuration of the three presented alternatives

The costs for the three alternatives are compared in Fig. 11 , counting with the 2 converters required (in each end of the line). It has also been taken into account the additional converter that is needed for the reactive compensation in HVAC.

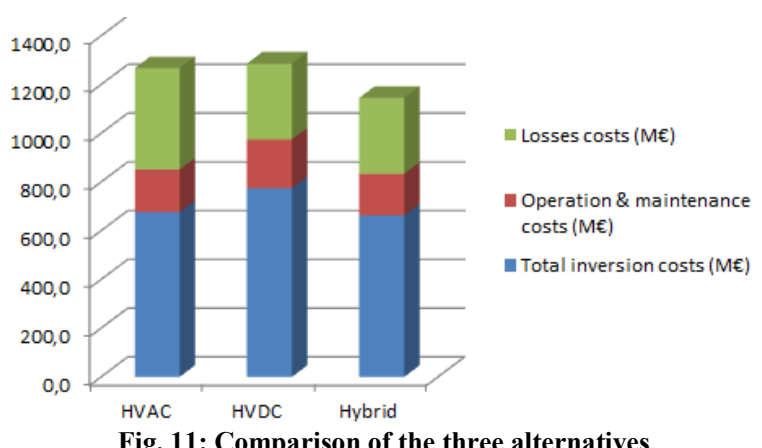

As it has been shown, HVDC substations are much more expensive than HVAC ones. Conversely, HVDC lines are cheaper than HVAC ones. For this reason, HVDC alternatives are so competitive when large distances are considered. There is a critical point where the costs for both configurations converge (Fig. 12).

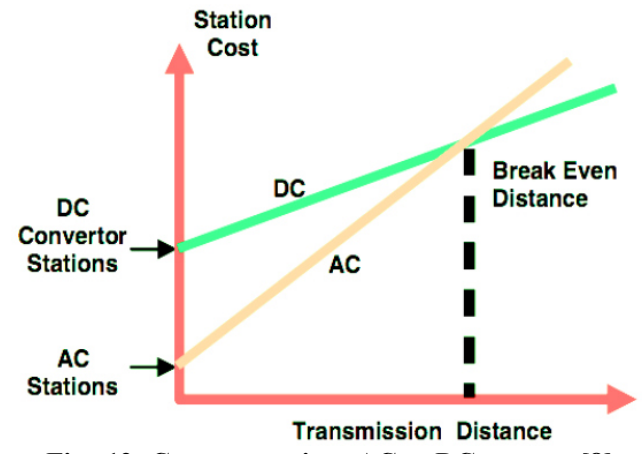

Fig. 12: Cost comparison AC vs DC systems [8]
According to the cost comparison shown, there is a point (break even distance) from which transmission system is more economic in DC. Thus, when systems longer than $1.000 \mathrm{~km}$ were considered, alternative 2 and 3 would be benefited. On the other hand, when shorter systems (600 $\mathrm{km}$, for instance), HVAC solution would be the most benefited.

There is a particular study that is interesting to be tackled: the three alternatives with the same parameters, only changing the number of substations. An application for this example could be an intermediate load substation. Results for this scenario are presented in Fig. 13 and 14.

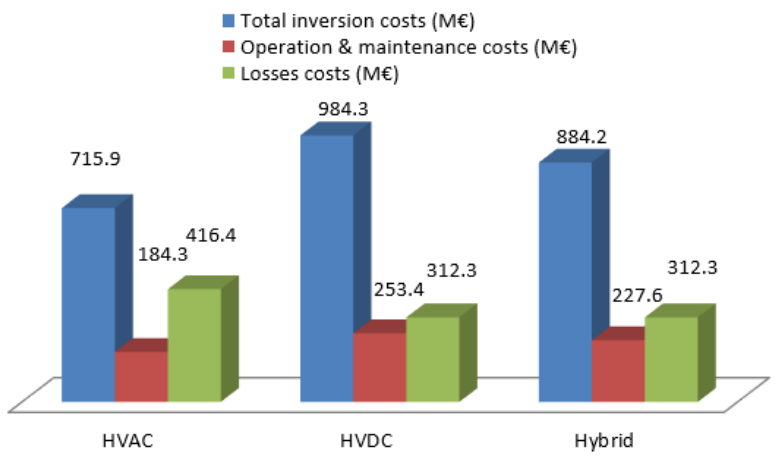

Fig. 13: Costs for the three alternatives -3 substations scenario

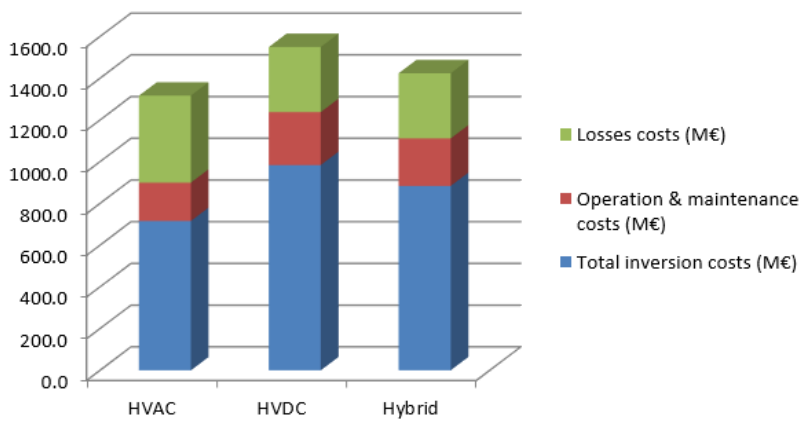

Fig. 14: Comparison of alternatives - 3 substations scenario

As previously explained, HVDC substations require a big investment and this is the reason why HVAC could be really competitive. In this scenario, HVAC alternative is the most economic one, presenting lower costs than HVDC.

In addition to this, this is not the only reason why HVAC alternative could be a valid option. In scenarios where the distance transmission is shorter, HVAC will also reduce its costs. To show an example of this application, a system of $600 \mathrm{~km}$ is considered. For the development of this scenario, only two substations are considered. Results for this scenario are presented in Fig. 15 and 16.

\section{Conclusion}

In order to integrate the bulk amount of renewable energy in Europe, it is necessary to reinforce the existing transmission system. One solution for achieving this is the development of a supergrid. In this paper, three different alternatives have been presented to comprise the supergrid. The two first alternatives need the installation of an upper module, while the third option consists in the conversion of the AC transmission system to a hybrid 
transmission system, being also required a big modification of its configuration to keep the current HVAC capacity and to guarantee an optimal weight distribution.

An interesting application for the upper module is the use of a compact configuration. This would help to achieve an optimal configuration in relation with electrical distances and weight.

The three possibilities enhance the capacity of the system, reducing the inversion costs and the environmental impact compared with the construction of new lines. Alternative 3 is the most cost-effective solution when long lengths between substations $(1000 \mathrm{~km})$ are considered. Nevertheless, this alternative has the inconvenience that it would imply a big modification in the tower structure and would lead to a temporary power cut. Besides, the complexity of works indicates that labour times could be very long. Due to these difficulties, for shorter lengths $(600 \mathrm{~km})$ the first alternative for the European supergrid could be the most attractive.

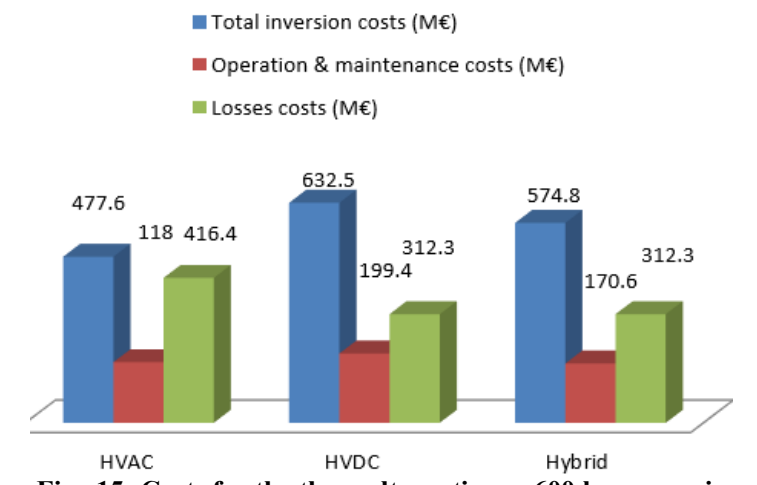

Fig. 15: Costs for the three alternatives $-600 \mathrm{~km}$ scenario

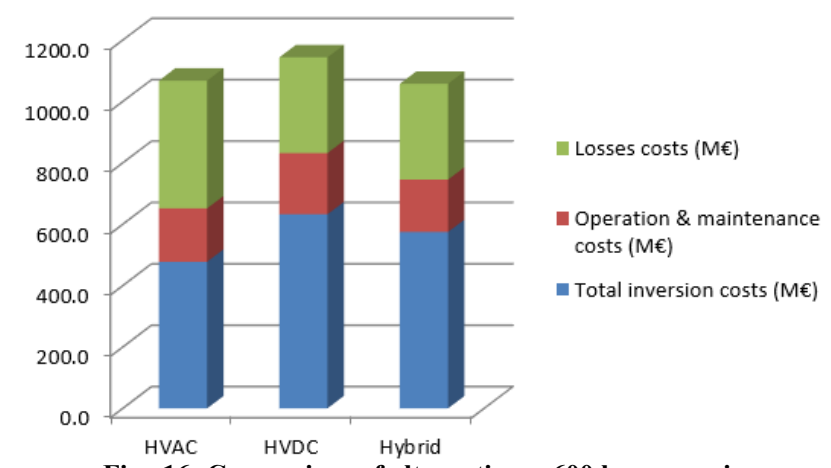

Fig. 16: Comparison of alternatives - $600 \mathrm{~km}$ scenario

\section{Acknowledgement}

This work has been supported by the Spanish Ministry of Science \& Innovation under grant ENE2013-48428- C2$1-\mathrm{R}$.

\section{References}

[1] Dirk Van Hertem and Mehrdad Ghandhari, "Multi-terminal VSC HVDC for the European supergrid: Obstacles". Renewable and Sustainable Energy Reviews 14 (2010) 3156 3163.

[2] Hakan Ergun, Barry Rawn, Ronnie Belmand and Dirk Van Hertem, "Optimization of Transmission Technology and Routes for Pan-European Electricity Highways Considering Spatial Aspects". Department of Electrical Engineering, division ELECTA. University of Leuven, Belgium.

[3] Noman Ahmed, Staffan Norrga, Hans-Peter Nee, Arf Haider, Dirk Van Hertem, Lidong Zhang and Lennart Harnefors, "HVDC SuperGrids with Modular Multilevel Converters - the Power Transmission Backbone of the Future". 2012 - $9^{\text {th }}$ International Multi-Conference on Systems, Signals and Devices.

[4] J. Lundkvist, I. Gutman and L. Weimers. "Feasibility Study for Converting $380 \mathrm{kV}$ AC Lines to Hybrid AC / DC Lines". EPRI's High Voltage Direct Current \& Flexible AC Transmission Systems Conference. Westminster, CO, USA. November 5-6 2009.

[5] S. Kishore Teegala and S. Kumar Singal., "Economic Analysis of Power Transmission Lines using Interval Mathematics". J Electrical Engineering Technology 2015; 10 (4): pp. 1471-1479

[6] Andrés Granero, "Ventajas e inconvenientes de las tecnologías HVAC y HVDC". Ingeniería de Máquinas y Sistemas Eléctricos. (2016).

[7] Sven Rüberg, Helder Ferreira, Angelo L'Abbate, Ulf Häger, Gianluca Fulli, Yong Li and Johannes Schwippe, "Research, methodologies and technologies for the effective development of pan-European key grid infrastructure sto support the achievement of a reliable, competitive and sustainable electricity supply". Technical University Dortmund (TUDo). Project no 219123.

[8] Armando L. Figueroa - Acevedo, Michael S. Czahor and David E. Jahn, "A comparison of the technological, economic, public policy, and environmental factors of HVDC and HVAC interregional transmission". Wind Energy Science, Engineering, and Policy (WESEP), Iowa State University, Ames, IA, 50014, USA. 